\section{KwieKulik as an Unknown: A Neo-Avant- -gardist Laboratory of Experience}

DOI: $10.18318 /$ td.2017.en.2.5

"The most fascinating couple in the history of Polish contemporary art" and "a legendary duo," claims the author of a magazine column dedicated to the life and work of KwieKulik. ${ }^{1}$ These sentiments are mostly correct. However, the problem is that Polish contemporary art history has never truly dealt with the "major event" that the duo's work undoubtedly constituted. A contemporary examination of their ideas and contrasting them with the trends prevalent in Polish art of the 1970s and the 1980s demonstrates that the duo was more or less a revelation - their work was ahead of the predominant artistic practices by about twenty or even thirty years. The practices of KwieKulik far exceeded the average perceptual habits, and invalidated much of the aesthetic canon. Back then, critics had no instruments or adequate language that would allow them to properly describe the duo's efforts, while contemporary artists often make inadvertent references to the former's work. ${ }^{2}$

1 Adriana Prodeus, "KwieKulik: Duet-legenda" ["KwieKulik: Legendary Duo"], Newsweek, February 28, 2015, http://kultura.newsweek.pl/ kwiekulik--duet-legenda,104269,1,1.html, accessed March 1, 2015. If not otherwise specified all translations of referenced works are provided by the translator of the article.

2 Dr. Luiza Nader has been working tirelessly for years to further our understanding of the efforts undertaken by the KwieKulik
Work on this text has been supported by the National Science Centre under the Grant DEC-2013/11/N/ $\mathrm{HS} 2 / 03509$.

\section{Agnieszka Dauksza}

- Postdoctoral researcher at the Department of Literary Anthropology and Cultural

Studies, Jagiellonian University. Author of Kobiety na drodze. Doświadczenie przestrzeni publicznej w literaturze przełomu XIX iXX wieku [Women on the Road. The

Experience of Public Space in Fin-de-Siècle Literature] (2013), Klub Auschwitz i inne kluby. Rwane opowieści przeżywców [Club Auschwitz and Other Clubs. Tattered Stories of the Survivors] (2016), and Afektywny modernizm [Affective Modernism] (2017). 
This essay will problematize a couple of ambiguities and potentialities inscribed into KwieKulik's body of work. Thus the formula for the title. I see the duo as an "unknown," which is a clear reference to one of their works, Activities with the Unknown $X$, wherein the artists suggested that the viewer imagine "all of the possible spatial relations of $X$ " and "see that unknown as something real, something that can take place, takes place, or cannot take place."3 In treating KwieKulik as an unknown, I am proposing that we look at their body of work all over again, suspending or reevaluating any prior interpretations, reexamining those "possible spatial relations" and potentialities, and probing for a language that would allow us to adequately analyze these practices.

Starting with the context of everyday life experiences in the Polish People's Republic, I will reflect on the laboratory-like conditions in which KwieKulik works were crafted. The problem here lies in a specific contradiction emerging in the confrontation of the duo's avant-garde rhetoric of with the character of their actual efforts. I am talking here about the essentially paradoxical because ostensibly incompatible with their manifested presuppositions mechanism of affective characterization (and, possibly, motivation) of (neo) avant-garde gestures, which, although not specific to KwieKulik, allows us to see their body of work from a different perspective when fully diagnosed and described.This ties into another problem I consider interesting, particularly the problem of power, domination, violence, or alternatively pressure, its influence exerted on a number levels: between the partners themselves (and their loved ones), between the political and communal system with the KwieKulik duo, and between the artists and their audience.

\section{In the Laboratory of Experience}

In conversation with Ryszard Ziarkiewicz, Kulik defines the work of the duo in the following way:

duo and I have to thank her for the inspiration (first movement). I would also like to thank Mrs. Zofia Kulik for sharing her photographs, reading through this essay and providing relevant commentary that helped me "think" and "feel" the realities which KwieKulik worked in. My thanks also to Dr. Tomasz Załuski for sharing previously unpublished writing with me and for his help with obtaining much needed source material.

3 See a description of that project: KwieKulik. Zofia Kulik \& Przemysław Kwiek, ed. Łukasz Ronduda and Georg Schöllhammer (Warszawa, Wrocław, Wiedeń: Museum of Modern Art, BWA Wrocław - Galleries of Contemporary Art, Awangarda Kontakt Gallery, The Art Collection of Erste Group and ERSTE Foundation, 2012), 188; Alicja Kępińska, Nowa sztuka polska w latach 1945-1978 [New Polish Art 1945-1978] (Warszawa: Wydawnictwa Artystyczne i Filmowe, 1981), 154 . 
There are many definitions of the avant-garde, but I mostly agree with what you're saying [i.e. Ziarkiewicz's definition of the prototypical avantgarde artist as a "dispassionate intellectual, leftist, and structuralist" author's note]. Intellect - yes, theoretical background, principle before practice, anti-subjectivism, questioning of the status quo. [...] Of our art, we say that it is a "reaction to experiences, especially unpleasant ones." [...] on the one hand, we coerced ourselves to comply with the strict regimen of collaborative work, [...] while on the other we rebelled against such submission, and that rebellious streak grew. ${ }^{4}$

This nexus of ostensibly incompatible notions is highly interesting to me, not only because it is typical of Kulik's assertion quoted above, but because it essentially characterizes the practices of the duo. On the one hand, it acknowledges the (fairly stereotypical) avant-garde ideals, including the belief in the legitimacy of the scientific and theoretical foundations of artistic works, as well as their intellectualism and anti-subjectivism.

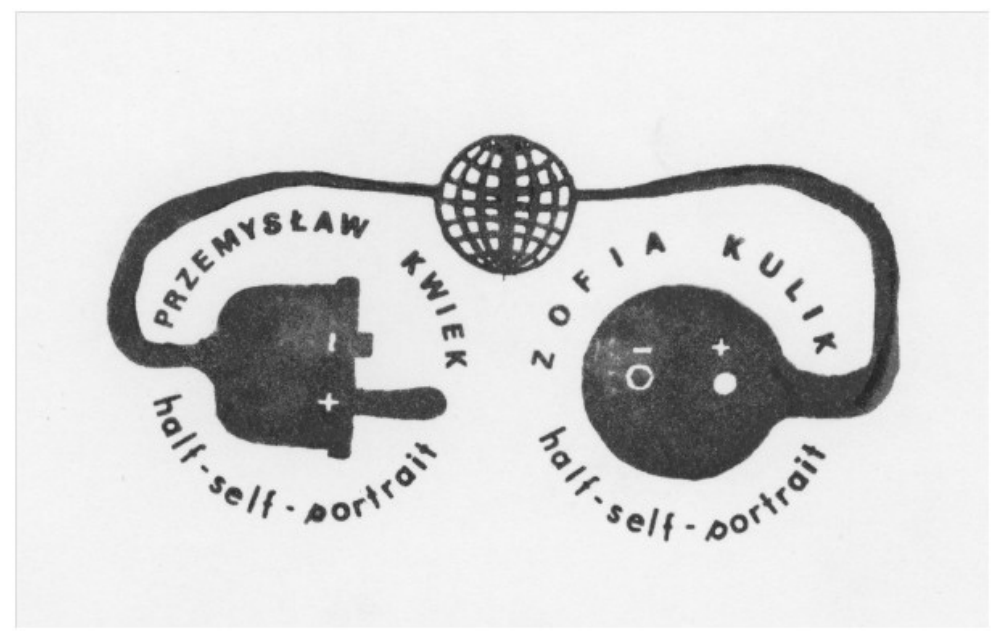

II. 1. Author: KwieKulik. Courtesy of Zofia Kulik.

On the other hand, however, the artist subverts, at least to some extent, the model of autonomous art, defines the efforts of the KwieKulik duo as a reaction to certain experiences and admits to have drawn inspiration from that

4 Ryszard Ziarkiewicz, "Bądź tylko posłusznym instrumentem. Z Zofią Kulik rozmawiał Ryszard Ziarkiewicz" ["Be Nothing More Than a Obedient Instrument: A Conversation with Zofia Kulik"], Magazyn Sztuki 1 (1993): 12-21. 
which is individual and rooted in experience, including the emotional tensions between the artists themselves. In another conversation, Kulik argues:

Psychology, obviously, was a concern, but in art, invoking some psychological ramifications or intentions or doubts, no, that was considered simply shameful, embarrassing, and everyone struggled to seem like a strong person, someone who could take it all and remain unruffled. 5

We seem to come back to the question of the affectivity of (neo)avant-garde art which, as demonstrated by numerous examples, was not so much a direct "distillate" of emotions and affects, as it was a sphere of friction, complementation, or equivalence between what was considered rational and objective with the amalgamate, the affective, or the traumatic. ${ }^{6}$ It was important, therefore, not to purge art of experience, but a more original processing thereof, for example, in the name of Kulik's principle to "avoid being too much of yourself in art."7 In the case of KwieKulik, the dissonance between the slogans they preached and their actual practice is prominent already in the titles of their individual efforts, including Art of Nerves, Killjoy Hardships, The Experiencing Monument, Make your Way rather than Puke your Way Through Life, Head Activities, Begging for Forgiveness, Let there be Mass Hunger or Alice in Fucking Wonderland. Importantly, they indicate not only the complication of the relationship between spheres that are customarily perceived as oppositional, but also indirectly reveal the stakes of KwieKulik's artistic game, as their artistic efforts were part of a "total," all-encompassing project. The artistic duo wanted to erase the lines between art, science, and experience/ existence, and simultaneously revolutionize the form of artistic expression. We need to emphasize, however, that talking about "art," "artwork," and "expression" is, to some extent, a distortion and simplification at the same time. The artists, assuming a processual character of their efforts, created their own, separate lexicon; ${ }^{8}$ they called their own works "efforts," "documentation of efforts," "aesthetic time-effects," etc.

5 Zofia Kulik, KwieKulik, dir. Joanna Turowicz and Anna Zakrzewska (2011; Warszawa: Centrala), $10 \mathrm{~min} .50 \mathrm{sec} .-11 \mathrm{~min} .25 \mathrm{sec}$. Courtesy of the Museum of Modern Art in Warsaw.

6 I am talking here about a certain principle that I have discussed more broadly in Agnieszka Dauksza, "Afektywny awangardyzm" ["The Affective Avant-garde"], Teksty Drugie 1 (2014).

7 Zofia Kulik, "Fragmenty teoretycznej pracy dyplomowej Z. Kulik. Rzeźba filmem" ["Fragments of Z. Kulik's Senior Thesis. Sculpting with Film"] in KwieKulik. Zofia Kulik \& Przemysław Kwiek, 420.

8 KwieKulik. Zofia Kulik \& Przemysław Kwiek, 463-470. 
The remarkableness of KwieKulik's practices stems also from their ability to reconcile the contradictions between traditional indicators of "dispassionate," "analytical," and "scientific" avant-garde with the personal and quotidian. This entailed transforming experience into the subject of experimentation. Back then, the duo operated according to a method I tend to call the artistic laboratory of experience. It involves the scientific examination of the dimensions of our surrounding reality, including the subjective, psychophysi$\mathrm{cal}$, and affective, through the medium of art. The scientific character of these practices calls for further discussion.

When Kulik brings up art as a "reaction to experience, especially unpleasant ones," what she means is not only the difficult nature of her personal and professional relationship with Kwiek, but also the everyday reality of the Polish People's Republic. The latter served as one of the most important reference points in the duo's body of work, a fact especially evident in, for example, Koło KwieKulik [The KwieKulik Circle] - a piece submitted to the 1977 edition of documenta in Kassel - which explored the differences between Eastern and Western European art. The piece is comprised of eight photographs with captions, portraying the artists' closest surroundings. ${ }^{9}$ The pictures have been arranged in a circle; the depicted environs include the 80-meter-tall neon sign over the "Prażanka" off-license store above which the artists lived and worked, a dirty passageway, and even dirtier stairway which store customers treated as their latrine, and so on. According to numerous accounts, as a result of these rather unfriendly circumstances, the artists had to completely cover their windows with particle boards, while the apartment door, held together with string and always slightly ajar, did nothing to filter out the smells and sounds coming in from the stairway which contributed to Kulik's emotional distress.

Naturally, lodging difficulties were back then accompanied by widespread problems with procuring groceries, artistic supplies, securing passports, etc. Intent on making a living, the KwieKulik duo took commissions (only a handful, but still exhausting) from government-affiliated artistic and craftsmanship institutions. This, in turn, worsened their fatigue and further embittered the duo, which was increasingly evident in their work; Kulik called it "a phantom struggle against existing reality," rearing its head in times of "accumulating fear of and anger at being misunderstood."10 These negative states of mind were further reinforced by tensions inside their social circles, the feeling of being unappreciated, as well as the political conflicts that the

9 KwieKulik. Zofia Kulik \& Przemysław Kwiek, 235.

10 Dorota Jarecka, "Musiałam mieć ciało" ["I Needed to Have a Body"], http://www.kulikzofia.pl/polski/ok3/ok3_jarecka.html, accessed February 28, 2015, 
duo were entangled in and their repercussions (as a result of the publication of their Gypsum Bird and Dick Man in a Swedish catalog, the artists were banned from representing Poland internationally; they were also denied passports and stripped of prospects for paid artistic work).

The title The KwieKulik Circle has dual meaning - it denotes the shape in which the photographs are arranged, but also provides insight into their closest surroundings and the context of that period, implying that the artists were trapped in a "vicious circle." By submitting their work to a lecture on the differences between Eastern and Western European Art, the KwieKulik duo did not want to emphasize the specific aesthetic, stylistic, or ideological character of art created in Poland as much as to spotlight the fundamental obstacles that the reality of the Polish People's Republic placed before any artist interested in creative work.

Regardless of the shift in Kwiek's or Kulik's attitudes - ranging from ideological involvement driven by active criticism, through the good-faith belief in the necessity to improve a faulty system, up to disillusionment with communism and embracing a leftist outlook laced with a measure of distrust towards the authorities - the duo managed to devise a method which, in Kulik's opinion, allowed them "to experience their own lives in art." The artists assured that their project, "total in nature," intended to integrate a number of different orders, thus allowing one to deal with one's experiences through art and treat artistic activity as a life unto itself. To quote Kulik:

We essentially lived as if were studying reality, conducting some sort of workshop study. And our life was also de facto such a study on its own. We studied our own selves under specific conditions and circumstances - in our writings we even pointed out that we saw ourselves as laboratory animals for our own inquiries. Living in this reality, we were continuously both inside it but also outside, as its detached analysts. Throughout this time, we were situated in this envelope - nowadays, we'd call it the privacy envelope or the studio envelope. It is possible that in our efforts, we've expanded the studio and allowed it to cross-over into reality, rather than tried to introduce reality into the studio.11

This led to the incessant and quite literal blurring of the lines separating existence and art. The duo spent whole days immersed in creative work, often transforming "both galleries and streets into artistic spaces, even their own apartment was turned into one such space, later christened the Action,

11 KwieKulik. Zofia Kulik \& Przemysław Kwiek, 539. 
Documentation, and Dissemination Workshop."12 They spent long hours engaged in fervent discussions which allowed them to conceptually work through their experiences. They used whatever was at hand: their own bodies, objects of everyday use, simple artistic supplies. Regardless of whether they were at home or outdoors, they always had a camera or video camera with them. They shot hundreds of photographs and diafilms. Capturing, or as the artists themselves called it, "documenting" their efforts was of crucial importance to their work. It was by no means casual - they were engaged in an essentially permanent process of documentation. A couple of years later, Kulik reappraised their work in that period:

it was drastic - exerting this influence on oneself, on one's own life, I see it more clearly today. Back then it felt natural, maybe we were simply trying to vent, to deal this way with the reality outside our workshop, outside our apartment. ${ }^{13}$

Particularly drastic elements of their practices includes their scale, frequency, and considerable level of energetic emotional commitment. It would be a mistake to think that these practices were undertaken only to provide an emotional outlet and a documentation opportunity. It is not without reason that such an imperative to study and analyze in a scientific manner clearly emanates from the above-quoted passage from Kulik, seeing as the KwieKulik method was bent on experimentation. However, the experiments launched by the artists were methodical, avoiding improvisation - their efforts were meticulous, repetitive, and aimed at producing artistic effects. That is why I believe that lab work categories should be used to examine the efforts and practices of the said duo. As is known, working in a scientific lab necessitates precise, consistent, time-intensive, rarely impressive, multi-staged, and interdisciplinary research that is varied and repetitive; the ultimate innovativeness (if any) is earned through constant experimentation, simulation, and exploration of every possible aspect of a given object or phenomenon. The question of the limits of laboratory space is also important. In the quote above, Kulik ponders the actual situation of the duo: "Throughout this time, we were situated in this envelope [...]. It is possible that in our efforts, we've expanded the

12 Marianna Michałowska, "KwieKulik i Rzeczywistość" ["KwieKulik and Reality"], http:// www.kulikzofia.pl/polski/ok2/ok2_michalowska.html, accessed February 28, 2015.

Zofia Kulik, Forma jest faktem społecznym. KwieKulik [Form Is Social Fact. KwieKulik], dir. Agnieszka Mazanek and Krzysztof Landsberg, (2009; Warszawa: Pop TV, TVP S.A., NInA), ca. $12 \mathrm{~min} .25 \mathrm{sec}$ - $12 \mathrm{~min} .40 \mathrm{sec}$. , http://ninateka.pl/flm/kwiekulik-forma-jest-faktemspolecznym, accessed February 28, 2015. 
studio and allowed it to cross-over into reality, rather than trying to introduce reality into the studio." I believe that the "envelope" that Kulik is talking about is the laboratory space.

Bruno Latour, defining that space for his own purposes, argues with absolute certainty that "the very difference between the »inside « and the »outside«, and the difference of scale between »micro« and »macro « levels, is precisely what laboratories are built to destabilize or undo."14 Obviously, in the rhetoric of the KwieKulik duo, the "studio" corresponds to the "inside," while "reality" to the "outside." Nevertheless, the efforts of the duo mostly entailed the erasure of the difference between these two domains, allowing one to cross-over into the other, both on the micro scale (of a given piece which could not exist as a complete artwork, but was only a fragment of a continuous process), and the macro scale (the understanding of the relationship between life and creative work and between the private and the political). Kulik asserted: "It wasn't the creation of pure art, ready, finished artworks. It was a whole web of relationships between art and life." Łukasz Ronduda, on the other hand, convincingly characterized that tension on the "macro" scale:

KwieKulik continuously problematized the line separating the public from the private imposed by the Communist state. They attempted to define the relationship between the two differently, basing their new definition not around a binary opposition, but rather around cross-permeation, creating a specific "mutuality."15

These relationships, permeations, and mutualities are the fundamental concepts behind the contemporary Latourian laboratory. As we transplant these concepts into the humanities, as attempted by Ryszard Nycz, Ewa Rewers, ${ }^{\mathbf{1 6}}$

14 Bruno Latour, "Give Me a Laboratory and I Will Raise the World," in Science Observed: Perspectives on the Social Study of Science, ed. Karin Knorr-Cetina and Michael Mulkay (London and Beverly Hills: Sage, 1983), 143.

Łukasz Ronduda, "Sztuka, miłość, polityka, nauka. Życie i twórczość Zofii Kulik i Przemysława Kwieka w latach 1970-1987" ["Art, Love, Politics, Science. The Life and Work of Zofia Kulik and Przemysław Kwiek, 1970-1987"] in KwieKulik, Zofia Kulik \& Przemysław Kwiek, 12.

Ewa Rewers, "Praktyka jako badanie: nowe metodologie w humanistyce" ["Practice as Inquiry: New Methodologies in the Humanities"] in Teoria - literatura -życie. Praktykowanie teorii w humanistyce współczesnej [Theory - Literature - Life. The Practice of Theory in Contemporary Humanities], ed. Anna Legeżyńska and Ryszard Nycz (Warszawa: Wydawnictwo IBL PAN, 2012). 
or Arkadiusz Żychliński, ${ }^{17}$ we may naturally treat them only as a metaphor for the cultural development of certain values. However, as suggested by Nycz,

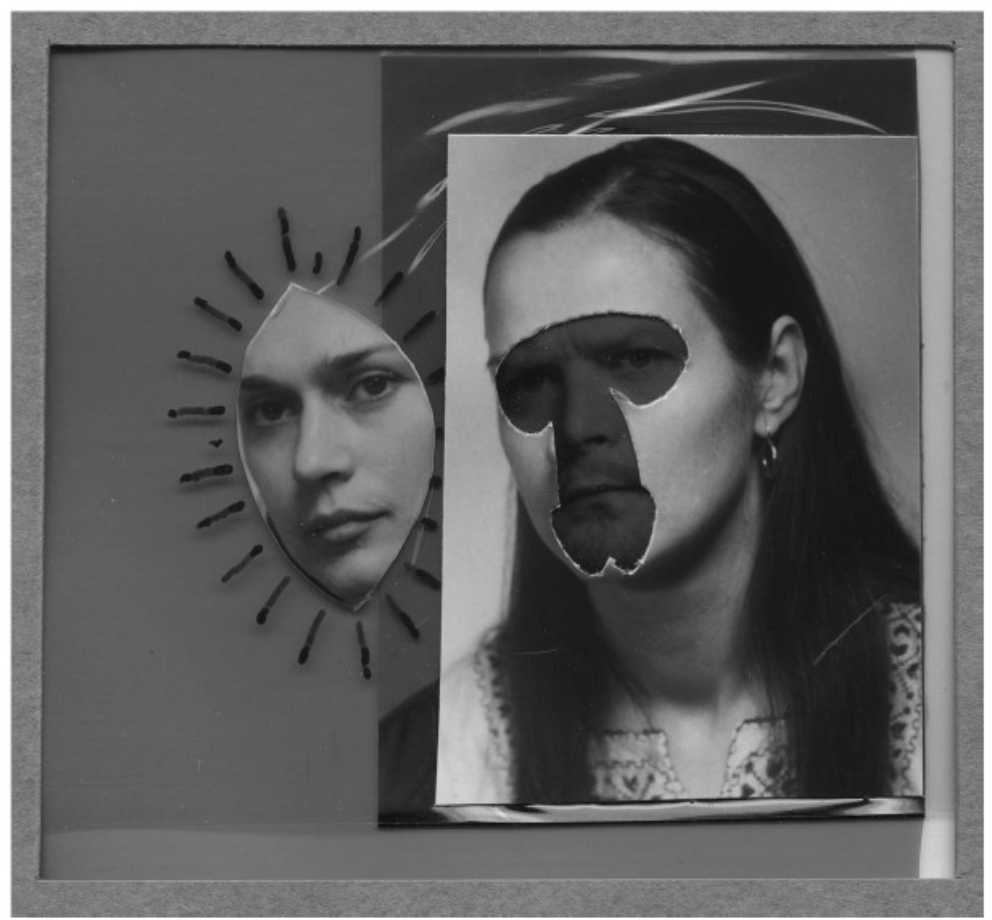

II. 2. Author: KwieKulik. Courtesy of Zofia Kulik.

every text of culture, as the foundation of an innovative humanities, actually is a laboratory; that is, it may be considered a "nexus of an open network of translational operations between what is natural, societal, and discursive, mediatizing and innovatively transforming relationships between mind, body, and environment."18 This means, therefore, that text understood laboratorywise does not deposit specific meanings as much as create a web of relationships between what is represented, historic, and situated on the side of the reader and that which creates the reader's specific context. As a result, these relationships "permeate and transform the historical, societal, and cultural

17 Arkadiusz Żychliński, Laboratorium antropofikcji. Dociekania filologiczne [The Laboratory of Anthropofiction. Philological Inquiries] (Warszawa: Wydawnictwo IBL PAN, 2014).

18 Ryszard Nycz, "W stronę humanistyki innowacyjnej. Tekst jako laboratorium" ["Towards Innovating Humanities. Text as Laboratory"], Teksty Drugie 1/2 (2013): 252. 
environment."19 The text is a laboratory-like field of the artist's experimental efforts; however, the interaction between text and readers also becomes a sphere of trial and experiment, a pretext for the reader/audience to practice innovativeness. Inasmuch as the suggestion to examine the literary text from this perspective requires a measure of scholarly openness that would allow the revision of prior models of literature, it seems that the specific nature of the KwieKulik project actually demands the assumption of such a perspective. Why?

Well, it may be difficult for the more traditional critical instruments to encompass the broad spectrum and simultaneously understand the stakes, style, and mechanism of KwieKulik efforts. When I mentioned the duo's proclivity for experimentation, what I meant was the actual subjection of oneself and one's own reality to trial. That is not all, however. I also meant infringing upon existing conventions, developing novel forms of expression, archiving art (their own and their contemporaries), and political commentary, as well as attempting to induce actual societal change. Efforts aimed at implementing these objectives were conducted in a very consistent manner. Over a dozen years, they expanded and confirmed their main, incredibly cohesive method. As accurately pointed out by Marianna Michałowska, KwieKulik activities were always driven by "the principles of logical reasoning, with every stage naturally arising from its predecessor," which "distinguished the KwieKulik method from the average artistic action or happening. There was no place there for improvisation or inadvertence. Every one of their efforts was preceded by a sort of script - a breakdown of sorts." 20 It was essential to them that they not only record individual activities, but also document their entire creative process.

And indeed, like any good research effort, all of their actions were preceded by extensive discussion, followed by the drafting of a meticulous breakdown of the particular artistic situation: identifying the spatial and temporal coordinates, describing the objects, their provenance, qualities, and purpose, capped off with outlining the artists' own motives. Their records resemble precise drugstore formulations. The status of artistic objects is also striking. Most often they were simple household objects contrasted with simple artistic supplies. Unlike Duchamp's famous urinal, however, these objects were never detached from their everyday use for artistic purposes. Zbigniew Libera sees this ability to use these objects in such a creative, innovative manner as one of the basic markers of KwieKulik's inimitable style:

Nycz, "W stronę," 248. 
They developed their own distinct style using all the means at their disposal: grey packing paper, black-and-white photographs, white-and-red blotting paper. They created notice boards that resembled genuine ones found in factory hallways, impeccably copied the visual shoddiness of that era. My favorite of their works, The KwieKulik Circle, is a shocking documentation of their own surroundings: shabby walls, courtyards, streets - with the pictures arranged in a circle. No exhibition would take that piece. ${ }^{21}$

The question of documenting everyday reality resurfaces here, examined from a different angle. The duo not only thematized their own confrontations with their surroundings, the artists made them the direct subject of their work. And they did so using widespread, elementary, banal or otherwise ostensibly "unartistic" means.

We may even risk stating that the most rudimentary yet most wearisome, painful, or disappointing manifestation of reality were their greatest inspiration. To quote Kwiek: "Contrary to most other artists, we value these small inconveniences, small troubles, very highly. We lie in wait, particularly for the bad ones, in order to participate in them."22 Experience itself thus becomes the "object" of laboratory and artistic study. This is one of the sources of many an artist's proclivity, informed to some extent by Oskar Hansen's theories, to "isolate individual elements of all chaotic, spontaneous, and biographic events, to divide, classify, examine sequences, model, analyze, and verify, etc. - and to introduce clear evaluation criteria."23

In conversation with Kwiek and Tomasz Załuski, Kwiek justified the motivations for his inquiries in the following way:

What drove us to do those things, what drove our behavior? We wanted to go against the cultural mainstream of the 1970s in Poland [...] we believed it wholly unacceptable. By occupying our proud positions, we tucked ourselves away in our "laboratory." We did not reject this culture simple because it was government-sanctioned. We spurned it because we did not believe it measured up to the standards and examples that we

As quoted in Jarecka, "Musiałam mieć ciało."

22 Maryla Sitkowska, "Wywiad z Zofią Kulik i Przemysławem Kwiekiem. Warszawa 1986-1995 ["An Interview with Zofia Kulik and Przemysław Kwiek. Warsaw 1986-1995"], http://www. kulikzofia.pl/polski/ok2/ok2_wywiad1.html, accessed February 28, 2015,

23 Ibid. 
were seeing in all the relevant sources available to us: books, magazines, scientific seminars. ${ }^{24}$

It is widely known that Kulik and Kwiek frequented seminars and lectures at the University of Warsaw and the Polish Academy of Sciences, held by preeminent Polish scholars, including Tadeusz Kotarbiński, Stanisław Piekarczyk, Helena Rasiowa, and Władysław Tatarkiewicz. They also read philosophical and praxeological treatises. Under their influence, as pointed out by Załuski, they "demonstrated increased interest in the question of formalizing artistic efforts and tried to utilize and expose in their course certain models and structural and generative algorithms." ${ }^{25}$ Eventually, they began creating visual representations of mathematical and logical operations (such as Activities with the Unknown X or Activities with Dobromierz). Łukasz Ronduda offers an interesting interpretation of that tendency:

Rejecting the belief in the existence of a pure essence of art and in the utility of essentialist platforms, KwieKulik undertook an original action with their embrace of mathematics as the only possible, objective, or even universal ontology. For KwieKulik, mathematics and logic became the only entities capable of salvaging a universal platform of human communication after the collapse of modernist utopias. ${ }^{\mathbf{2 6}}$

Ultimately, although driven by scientific theories of activity, they failed to establish a platform of communication that would bring KwieKulik a broader audience, but they definitely contributed to their perception as innovators.

As argued numerous times by the artists themselves, the objective was to act against the autonomous avant-garde, as well as Socialist Realist art and ubiquitous shoddiness. Kulik and Kwiek argued, therefore, against officially sanctioned ideology and aesthetics. On one hand, they criticized the authorities and government institutions because, as committed leftists, they could not reconcile their beliefs with the "perversions" of the system. On the other hand, they also disparaged the anti-Communist opposition, claiming that "ideological identification exerts the maximum influence on us precisely

24 Tomasz Załuski, "Anatomia KwieKulik. Z Zofią Kulik i Przemysławem Kwiekiem rozmawia Tomasz Załuski" [The Anatomy of KwieKulik. A Conversation with Zofia Kulikand Przemysław Kwiek"], KwieKulik, Zofia Kulik \& Przemysław Kwiek, 539-540. in Action! Art and Scientific Discourses"] in KwieKulik,Zofia Kulik \& Przemysław Kwiek, 533. 
when we acknowledge the fact that we're not thoroughly identified with it."27 Not without reason, the KwieKulik duo seemed to believe that radical hostility towards the policies of the Polish People's Republic did not make the opposition pure, innocent or detached and that this exact radical intensity of their opposition allowed the authorities - by appropriating the attention and the sensibilities of the antagonist - to achieve considerable psychological, social, and ideological success.

On the other hand, the artists experimented on a variety of levels, including the aesthetic, the rhetorically symbolic, and the material. They devised a veritable laboratory of forms. They wanted to instigate a shift in the understanding of the role of the artist, but also - as we have already pointed out - in the relationship between art and existence. Moreover, they negated prior artistic achievements, including the model of modernist art. The proposed their own, original formal approaches - over a dozen years, the forms developed by KwieKulik kept evolving. Here, the innovative practices of a formal laboratory blended with the activities of a laboratory of experience, and not only in a figurative sense. Their efforts were highly inventive - by documenting, archiving, ${ }^{28}$ and commenting on the reality of the Polish People's Republic, they devised new ways and techniques of dealing with their own experiences and thus provoked a shift in people's attitudes towards their own realities; eventually (on the micro scale), this led to a partial modification in the status quo, although perceived differently by then.

\section{Under Pressure or What Happened Between K. and K.}

In 1979, KwieKulik were invited to an international event focused on creating "mail art," organized by Commonpress magazine. Over sixty participants developed original self-portrait-stamp designs which were later crafted by a specially commissioned firm. In order to somehow deal with the need to symbolically separate in the course of creating their self-portrait, the duo

27 Ibid.

28 See discussions and analyses of the efforts undertaken by Kwiekulik in the field of archiving, including Paweł Mościcki, "KwieKulik - archiwum działania" ["KwieKulik - Archives of Action"] in KwieKulik, Zofia Kulik \& Przemysław Kwiek, 520-522; Luiza Nader, "PDDiU: Archiwum horyzontalne" ["ADaDW: a Horizontal Archive"] in KwieKulik, Zofia Kulik \& Przemysław Kwiek, 523-524; Luiza Nader, "O czym zapominają archiwa? Pamięć i historie "Z archiwum KwieKulik«" ["What Do Archives Forget? Memory and Histories »From the KwieKulik Archives«"] accessed February 28, 2015, http://www.kulikzofia.pl/ polski/ok2/ok2_nader.html; Tomasz Załuski, "Zofia Kulik prezentuje KwieKulik. Dobromierz X. Katalog" ["Zofia Kulik Presents KwieKulik. Dobromierz X. Catalog"], accessed February 28,2015 , http://www.kulikzofia.pl/polski/ok2/ok2_zaluski.html 
undertook to perform a highly symbolic split. ${ }^{29}$ Kwiek, as the male potential, was represented by a power plug with a clearly marked prong. Kulik,

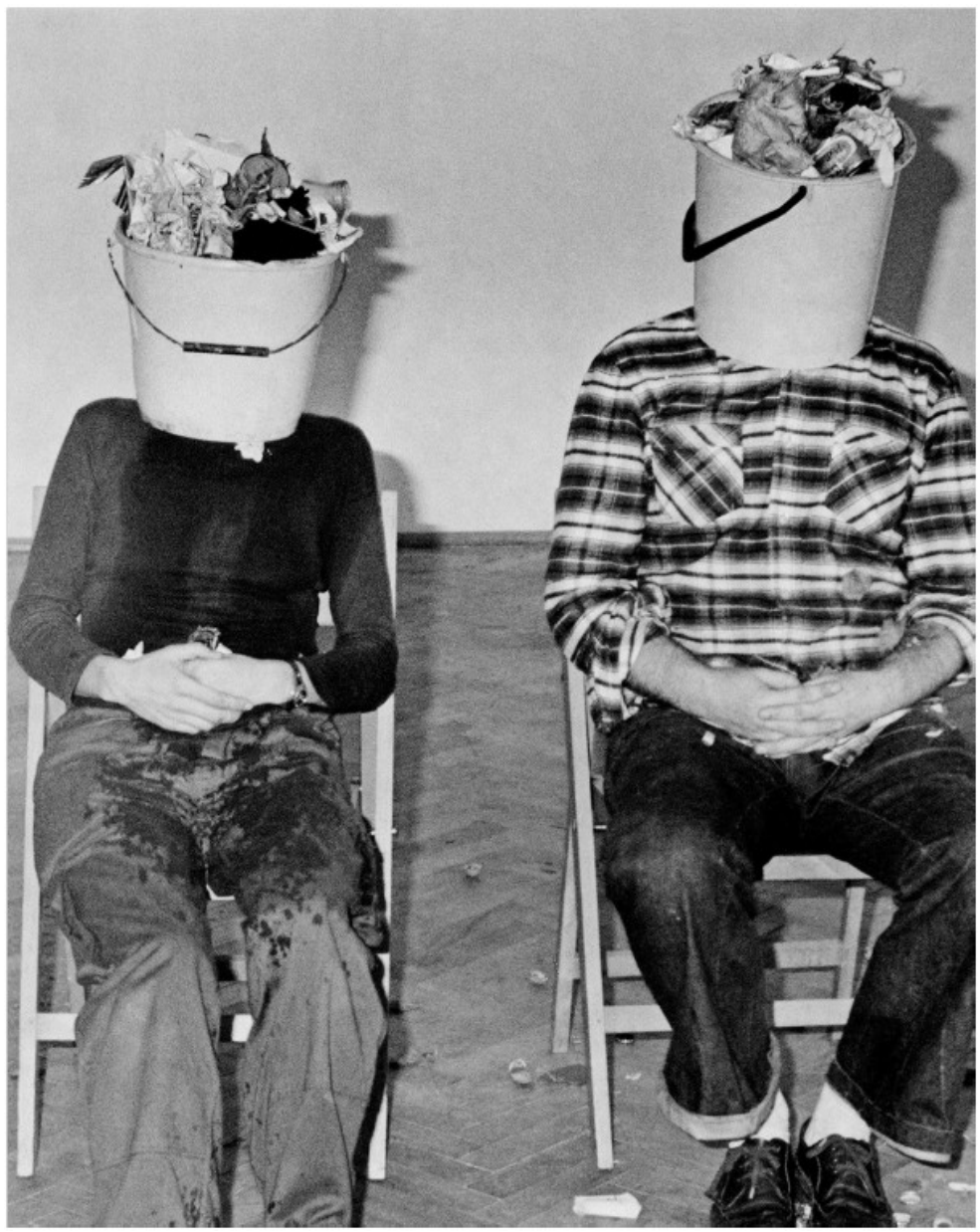

II. 3. Author: KwieKulik. Courtesy of Zofia Kulik.

the female potential, was represented by an electrical outlet. The potential combination of both elements could "stimulate" or "illuminate" the globe, here replacing a lightbulb. However, the prong with the "+" symbol was aimed at the hole bearing the same "+" symbol. One could surmise,

29 KwieKulik, Zofia Kulik \& Przemysław Kwiek, 325. 
therefore, that the electric potentials in both would simply end up repelling one another. A question arises: would the artists attempt to symbolically portray the misfortune of combining their potentials in such a public way, and if so, why? If we were to read the globe as a metaphor of their artistic practice, it would mean that the incompatibility of their potentials precludes the transmission of power, the system itself appears ineffective, and art is prevented from becoming a space or a medium for causal influence. We may naturally choose to see the artists' gesture as incidental or amusing, but it is difficult to shake the feeling that it actually says quite a lot about the mechanisms of their collaboration.

Were we to take a closer look at their practices, we would be struck by an accumulation of power, male domination, and even overt violence burdening the relationship. This was evident not only in their artistic efforts, but in their private and socio-political life as well - the latter being important due to the influence it exerted over their art. From this angle, the ostensibly trivial issue of food, often resurfacing in interviews, is particularly interesting:

Zofia Kulik: We lived in Warsaw back then, in the Praga district [...], while my mother lived in Mokotów [...]. The two are quite a ways apart from each other. Imagine that twice or thrice weekly I took public transport and went to my mother's and came back with two big baskets of food [...]. And that allowed us to survive. I got up before eight to walk the baby to daycare. On my way back I bought rolls, brought them home and he [P. Kwiek - author's note] always made a scene that they were stale.

Przemysław Kwiek: This was about the bread, not the rolls.

ZK: Rolls, too. He squeezed them to check whether they crackled just right. Besides, when he woke up so late for breakfast [around 1pm - author's note], I was already hungry after waking early, but he forbade me from eating. I was terribly skinny back then, skin and bones, nothing else. PK: That's correct, but pointless [...]. Nowadays they call it fitness. It was about something else, a sort of cohabitation statute, but enforcing it was a mistake. [...] the rule is you eat breakfast around 8 am and then don't snack between meals. I did the cooking back then and was afraid that if she munched on something before dinner, she wouldn't have eaten anything.

ZK: And dinner was around $6 \mathrm{pm}$. So I wasn't allowed to eat between morning and evening. ${ }^{30}$ 
This passage clearly demonstrates to what degree their everyday life was subordinated to the principle of methodic creation. The problem seems to lie, however, in the fact that the style and character of their artistic efforts was not a resultant of their mutual decisions, and that sacrifice in the name of art was definitely one-sided. To put it bluntly: the figure of Kwiek seems to loom over the relationship like a tyrant intent on enforcing his laws in both the private sphere and the sphere of aesthetics, as Kulik's psychophysiological subordination definitely impacted the level of her artistic dependence.

Kulik started out as a sculptor, creating finished, closed forms. Under the influence of open form theories developed by Oskar Hansen and following Kwiek's imperative, she abandoned her earlier efforts in pursuit of constant experimentation, constant action, of ceaseless, unending process. Kulik only "betrayed" Kwiek a couple of times, creating (often while away without him) a handful of "closed" forms. Rumor has it, however, that it was evident that she missed working on a more sizeable "finished" form. It was no secret that their mutual friends often ambiguously hinted at her to break out on her own: "Kulcia, when are you finally going to do something on your own, without Kwiek?"31 To some extent, she allowed herself to do just that a number of times in 1978, when she developed the performance Asking for Forgiveness after completing the joint performance Killjoy Hardships with Kwiek. For Asking, she borrowed a white dress with a long train and as she walked the stage, she repeatedly bowed and dropped to her knees before the audience. When asked later by Joanna Turowicz about her motivations, Kulik replied:

Working as a pair suffocated me: we were doing the same, saying the same. Bizarre emotions were welling up inside me [...]. I wanted to ask forgiveness of the audience, to beg at their knees [...]. But what was the audience supposed to forgive me? I do not know exactly. Maybe the fact that I am there, personally, even though it seems that I am. As one part of a two-figure hybrid which leaves me unaware of the role I have to play, what space do I occupy, what shape do I have [...]. I must have been quite pathetic like that. The humiliation I felt was total, all-encompassing. But I needed that situation so I put myself there. ${ }^{32}$

31 Karol Sienkiewicz, Zatańczq ci co drżeli [And the Trembling Shall Dance], (Kraków-Warszawa: Karakter, MSN w Warszawie, 2014), 38. wicz" ["The Neo-Avant-garde Artist Rebels. A Conversation with Zofia Kulik"], Opcje. Kwartalnik Kulturalny 3 (2004): 54-61. 
The pictures from the event show a sad yet excited Kulik walking alone before the bewildered audience. With Asking for Forgiveness, Kulik not only revealed the cracks in what was believed to be a monolith, demanding her position in the duo be acknowledged, she also courageously committed herself to an act of emancipation through humiliation. ${ }^{33}$ The ambiguous yet intensely expressive gesture fundamentally changed the relationship between the artist and audience and starkly contrasted the usually aggressive practice and rhetoric of the duo.

Kulik decided to break away only 10 years later. Curiously, the question of food and food-related anxieties resurface in conversations about her decision to return to solo work. As the artist confessed in one of the interviews, as she left Kwiek, she "began to worry about food, because all the cooking was always done by Przemek." Her ex-partner confirmed: "I did the cooking, but I'd been making these hot, spicy soups that she didn't like. A couple of years back she finally learned to cook and her meals were finally how she liked them: watered down." ${ }^{34}$ This somewhat spiteful remark reveals the fundamental conflict between the two, aesthetic rather than culinary.

An analysis of the records of the duo's practices reveals the tensions that wracked their relationship. We should point out specific examples of their influence-one of them involves a project the duo developed for another edition of the Commonpress competition, this time focused on "nudity on stamps." KwieKulik used their passport photographs and prepared a photomontage that could best be described using the term "sex stamps." In Kulik's face, a hole has been cut in the shape of male reproductive organs. In the hole, a photograph depicting Kulik's face was pasted and then taped over with red, transparent cellophane. Next to the manipulated portrait is a cutout of her face, shaped like a vulva, with black lines radiating away from it. The collage could obviously be read as a metaphor of their symbiotic relationship. ${ }^{35}$ It seems, however, that the photomontage is rather a visualization of symbolic appropriation. Insofar as Kwiek's phallic visage is brutally inserted into the figure of a woman, completely "annexing" her,

33 Cf. inspiring feminist analyses of KwieKulik efforts as well as Kulik's individual practice from the late 1980s and early 1990s, including Ewa Majewska, "Kłopot z płcią w pracach KwieKulik? Cherchez la femme" ["Trouble with Gender in KwieKulik Works? Cherchez la femme"] in KwieKulik, Zofia Kulik \& Przemysław Kwiek, 518-519; Ewa Toniak, Olbrzymki: Kobiety i socrealizm [Giantesses: Women and Socialist Realism] (Kraków: Ha!art, 2008); Izabella Kowalczyk, "Kobieta, która patrzy" ["The Gazing Woman"], Kresy. Kwartalnik Literacki 1 (1999); Magdalena Ujma, "Tkanie jako bunt. O twórczości Zofii Kulik" ["Weaving as Resistance. On the Work of Zofia Kulik"], Dekada Literacka 2 (2004). 
but simultaneously creating a highly consistent whole, both in terms of subjectivity and aesthetics (producing the appearance of "Kwiek with long hair"), the figure of Kulik is thoroughly dismembered and reduced to a "floating humanfaced vagina," always orbiting her partner.

One could find many more less obvious manifestations of the violent nature of the collaboration between Kulik and Kwiek. Undoubtedly, that character was not exclusively a result of their individual personal or characterological implications, but primarily a consequence of their laboratory-like work ethic, their attempt to treat the avant-garde imperative of keeping one's emotions in check and purging all weakness quite literally. By taking her leave of the relationship, Kulik unambiguously distanced herself from these methods and associated ideologies, adding: "For 17 years, I've been part of a duo. Participated in the pursuit of common goals. After multiple attempts, however, I no longer believe that they can be achieved, nor do I believe in conflict-free teamwork [...] I no longer wish to be a lab animal."36

\section{3. "Violent Struggle" as Source of Innovation?}

Multiple accounts suggest that when she was still with Kwiek, Kulik was withdrawn, shy, and unsure of her role and her position. But when it came to talking about their common efforts, she was restrained in arguing their artistic choices. Years later, in a conversation with Kwiek and Tomasz Załuski, she confessed that she yearned for her own space:

Zofia Kulik: I wanted us to introduce a division of labor in specific situations; then I could have done my work and he could have done his. We would have been more effective. But no, we were never apart for even a moment.

Przemysław Kwiek: No, we were a whole.

ZK: It was highly uneconomical. We were doing everything together, which deprived us of any work that we could have done on our own. Przemek said that in his opinion back then all our work should be highly systematic, clockwork-like. But it was his idea, he imposed it, by, for example, getting up only at 1pm, everyone else was left to conform to it [...]. Everything else had to be subject to his psychophysiological rhythm, dispassionately, like in a factory. ${ }^{37}$

36 Karol Sienkiewicz, "Zofia Kulik," http://culture.pl/pl/tworca/zofia-kulik, accessed February $28,2015$. 
It would seem that Kulik not only ate, but also worked on what she did not want to, and in a way that did not suit her by any means. All of this happened in the name of pursuing an alleged (artistic? scientific? societal?) duty, the fulfillment of the mythos of neo-avant-garde self-restraint, intellectuallization, and emotional detachment. Kwiek's assertions reveal how significant the essentially modernist desire for wholeness and the vision of a monolithic nature of the duo were to him. The question arises - were the duo's efforts, founded upon such and such values due to Kwiek's express wishes, but ostensibly signed by both artists, dominated primarily by Kwiek's influence?

Well, not necessarily, especially if we treat the artistic practice of KwieKulik as a sphere of agon. It seems that their actions and documentation efforts were an incessant confrontation of ideas, reasons, affects, and needs. And although everything indicates that Kwiek was dominant in the relationship, Kulik's passivity, submissiveness, and sometimes active and intense resistance definitely influenced the character of their practices. It is therefore crucial to be aware of the everyday toil that developing a common aesthetic quality requires. But that is not all. It also seems that KwieKulik's efforts, defined here as a polemic dialogue between two artists, can be seen as quite an ambiguous example of internalizing, maybe even overcoming, the broader problem of modernist aesthetic dualism.

Kulik often emphasized the differences in the worldview and artistic perspectives between her and Kwiek. In a conversation with Ryszard Ziarkiewicz, she asserted:

we were together, creating this peculiar personal and artistic collage. From an external point of view, we seemed like a "monolith." [...] However, from the inside, it was apparent that our attitudes were essentially incompatible, and that's why they were locked in a violent struggle. ${ }^{\mathbf{3 8}}$

The antagonism between the two was felt not only on the rhetorical level, but also in the different approaches to artistic work held by Kulik and Kwiek. Kulik's aforementioned performance, Begging for Forgiveness, is a highly illustrative example thereof, as well. Equally important were her "actions at large," including the one she performed while on scholarship in Milan, consisting of two separate efforts: 1 . She affixed pieces of her love letters to Kwiek to the doors of the Duomo (e.g. "My dearest, I long to be with you," "I often think about our baby,") which "interacted" with depictions of Biblical scenes sculpted on the doors; 2 . She sculpted formless clay figurines which she then arranged in a mock May Day Parade. The figures carried banners featuring

38 Ziarkiewicz, "Bądź tylko," 12-21. 
scraps of her letters to Kwiek (including "My love," “Dream," “you," "be," "My," "Dearest," "Miss you," "so much") and marched past the Palace of Culture and Science, constructed from one of the letters and stuck onto Kulik's suitcase.

In the meantime, Kwiek was busy creating pieces such as The Vernissage of Meat and Osęka, which ridiculed Andrzej Osęka for his public critique of the neo-avant-garde. The piece consisted of the art critic's photograph and a scrap of his essay stuck to a piece of raw meat all of it hanging from the ceiling on a string.

This arbitrary juxtaposition of the artists' individual efforts and their collectively developed aesthetic is supposed to facilitate the discussion of the mechanism of confronting Kulik and Kwiek's contrasting rationales and the practical aspects of their "violent struggle." It is not hard to identify fundamental differences between in their approaches: Kulik strived to create sparse, finished forms, sought conceptually and formally original forms that would allow the expression of "logical feelings" (a quality described by Kulik in a conversation with Andrzej Turowski), discuss gender and corporeality, and offer concise commentary of her own feelings, experiences, and reactions (evident in, e.g., Alice in Fucking Wonderland). Kwiek's practice, on the other hand, gravitated towards processual and violent influence, usually based on commentary-augmented critique of a given social/political phenomenon and the belief in the "missionary-like" character of the artists, whose "shockand-awe" efforts are supposed to shape beliefs and customs of the audiences. This superficial contrast clearly reveals the placement of emphases that ultimately decided the shape of the KwieKulik method. I assert that the ceaseless confrontation between different values, the need to maintain the state of incessant "violent struggle" and to constantly push their often contradictory arguments ultimately contributed to the dynamics, the variety, and the lasting timeliness of the duo's artistic efforts. To put it in simple terms, we could claim their jointly produced works were, at heart, a record of the internal tensions and conflicts wracking their relationship, conflicts which not only stemmed from their individual aesthetic preferences, but were also the resultant of their distinct sensibilities and experiences, both of which are gender-dependent.

Simultaneously, practices examined from this particular perspective may be seen as transcending traditional, dualist aesthetic divisions of modernism into intellectual and realistic, or empathetic art - that is, one usually affirming the feminine, the intimate, the emotional, the corporeal, and the irrational. The efforts of KwieKulik were a sort of third alternative, internalizing cracks and modernist divisions which, in turn, allowed use of and experimentation with means of "high culture" avant-garde and popular art. This new alternative allowed artists to problematize and blend different methods, styles, and subjects, such as political subjugation, ideological involvement, the conformism 
of communities, occasionally traumatic experiences of everyday life, romantic and familial relationships, one's own experiences, fears, and disappointments. Read in such a way, I have come to call KwieKulik's efforts as the art of affective realism (a concept which I will expound on in another essay ${ }^{39}$ ).

\section{Head Activities to "Experiential Thinking"40}

Here, I would like to briefly dissect one specific undertaking which not only combined an exploration of violence, interpersonal relationships, intimacy, and politics, but also accumulated the intense tensions that drove the dynamics of KwieKulik's efforts - Head Activities in Three Scenes presented at the Labirynt Gallery in Lublin in October of 1978. The effort was a "protest appearance," after the authorities denied issuing passports to the artists. The performance consisted of three sections:

Before entering the room, the attendees were asked to stick small red flags behind their ears [...] As they entered, they were seeing Kwiek and Kulik with heads stuck in the seats of two chairs. In the second section, Kulik sat on the floor with her head sticking out from the bottom of a washbowl. After pouring water into the bowl, Kwiek washed his face, pulled off his shirt, washed his armpits, and then took off his shoes, socks, and washed his feet. Kwiek then poured more water into the bowl, putting the water level slightly above Kulik's mouth but below her nose, so that she could breathe but couldn't speak. Then he put the tip of a knife against the back of her head and started to yell: "Go on, say something, you whore... You can't, can you...?!" In the third and final part, the attendees saw Kwiek and Kulik with trash can stuck on their heads (with holes cut in the bottoms). Then, two other artists [...] began to circle the duo, throwing trash previously taken out of a bin in the gallery corridor into the buckets. ${ }^{\mathbf{4 1}}$

The performance described above has to be one of the most oppressive in the entire history of KwieKulik. It blends at least a couple themes, problems, and techniques that the duo believed important. It definitely explores

39 Due to the space limitations, this issue will be explored in depth in a separate essay, KwieKulik jako zmęczeni terroryści. Sztuka realizmu afektywnego [KwieKulik as Tired Terrorists: The Art of Affective Realism] (to be released in print).

40 To quote a very apt term coined by Katarzyna Bojarska, cf. Katarzyna Bojarska, "Poczuć myślenie: afektywne procedury historii i krytyki (dziś)" ["Experiential Thinking: Affective Procedures in History and Criticism (Today)"], Teksty Drugie 6 (2013).

41 KwieKulik, Zofia Kulik \& Przemysław Kwiek, 294. 
the combination of the spheres of art, politics, privacy, and eroticism, here driven to the point of degeneration and vulgarity. Kwiek's brutal treatment of Kulik can be read as an expression of domination and contempt for her as a woman, partner, and artist who fails to strive for a stronger position in the duo; yelling "Go on, say something, you whore... You can't, can you...?!" could in such a situation be considered a harsh call on Kulik herself to assert her own artistic position.

The red flags (and other red objects) were artefacts of the New Red Art that the duo postulated; they also reference symbols and colors affiliated with the communist party. In this context, Kwiek's humiliating and intimidating behavior towards Kulik are a highly reflective of the mechanisms employed by the authorities and their methods of influencing the citizenry - allowing them to live, "breathe," but stripping them of any capability to speak (mouth below the water line) and restricting their mobility (knife pressed against the back of the head). From this angle, the title not only implies literal interaction with the head as body part, but also ideological manipulation and exerting political pressure.

I am especially interested in the question of violence and humiliation. Although Kulik was definitely the chief "victim" in the middle portion of Head Activities, in the final part the role of Kwiek shifted - once an aggressor, he was now another victim of oppression. But were the artists the only ones to be intensely experienced? Not necessarily. If we were to study the mechanisms driving many of the duo's efforts, we would definitely notice that we are dealing here with something that, like in the paintings of Francis Bacon, decides the final impression and the overall striking effect. Commenting on his own painting of Pope Innocent X, Bacon asserted the he "wanted to paint the scream more than the horror." In his analysis, Gilles Deleuze argued that:

As soon as there is horror, a story is reintroduced, and the scream is botched. In the end, the maximum violence will be found in the seated or crouching Figures, which are subjected to neither torture nor brutality, to which nothing visible happens, and yet which manifest the power of the paint all the more. This is because violence has two very different meanings [...]. The violence of sensation is opposed to the violence of the represented (the sensational, the cliché). The former is inseparable from its direct action on the nervous system, the levels through which it passes, the domains it traverses [...]. It is the same with Artaud: cruelty is not what one believes it to be, and depends less and less on what is represented. 42 
The audience, an important part in the performance of Head Activities, definitely had difficulty restraining their emotional reactions to the sight of Kwiek threatening Kulik with a knife. In that moment, the roles were defined very clearly: Kwiek was the oppressor, Kulik the victim, while the audience played witness. I assert, however, that the situation shifted radically in the third and final portion of the performance, when both artists, with trash cans on their shoulders with the heads inside, were inundated with waste from a bin in the gallery hallway. The thing was that the trash was picked out just before the performance, so the waste could have been discarded by anyone in the audience. This, in turn, made every member in the audience somewhat responsible for the humiliation suffered by the artists. The method was supposed to make people in the audience - flags stuck behind their ears - realize that the division into the oppressors and the oppressed, the involved and the passive, the manipulators and the manipulated is more or less illusory. Simultaneously, the audience was subject to what Katarzyna Bojarska penetratingly called "the takeover of power," that is "using the instruments of power which then allow artists, critics, and scholars to forcefully push their way into the sphere of public discourse." 43

Thanks to their highly ambiguous attitude towards the authorities, KwieKulik managed to avoid both cynicism and utopian anti-politicization. Additionally, thanks to their efforts there were finally "reasons to fear art."44 And indeed, the audiences of Kulik and Kwiek were exposed to both psychoaffective and physical pressure (for example The Experiencing Monument). The question arises: why did the artists provoke their audiences and what did they need such potent tensions for?

Paradoxically, despite the pain and distress they subjected their bodies to, Kwiek and Kulik saved the most intense experiences for their audiences. In the case of Head Activities, the violence perpetrated between the partners and the violence they were subject to when their heads were inundated with waste was the violence of the represented, predictable and trivialized by Deleuze. It was only the tension emerging between the audience, the artists, and an undefined yet hinted at political entity that turned out to be genuine violence of sensation, and as such the true stakes of KwieKulik's practices.

43 Cf. Bojarska's arguments in "Miłość do emancypacji. O warsztacie i zaangażowaniu badacza-humanisty z Piotrem Piotrowskim rozmawiają Luiza Nader, Katarzyna Bojarska i Adam Mazur" ["Love of Emancipation. Luiza Nader, Katarzyna Bojarska, and Adam Mazur Discuss Techniques and Involvement of Scholars of Humanities with Piotr Piotrowski"], http://widok.ibl.waw.pl/index.php/one/article/view/87/115, accessed February 28, 2015.

44 Maciej Gdula, "KwieKulik - przeciw cynizmowi, przeciw antypolityce" ["KwieKulik Against Cynicism, Against Anti-Politics"] in KwieKulik, Zofia Kulik \& Przemysław Kwiek, 514. 
The laboratory of experience and the laboratory of form allowed the artists to generate new experiences, meanings, and techniques. Their art was a continuous process, the perfect embodiment of what could be considered as cultural "verbness," 45 which Kulik once labeled as "functionality." In practice, it turned out that the artists not only sought new forms of verbalizing and dealing with experiences, but also propounded new formulas of experiencing reality. Their everyday efforts turned out to be not just a creative practice, but also a conscious and involved method of unharnessing oneself between experienced reality and its official representations (state, propagandist, Socialist Realist, etc.). Additionally, it also seems that the laboratory established by the duet and its inherent functionality, "processuality," or "verbness" were, by design, destined for the "long run." The clarity of expression of KwieKulik efforts is probably supposed to inspire the more contemporary audience to retroactively trigger new meanings in the course of the act of analysis, to reexperience and intellectualize them, and, as a result, to maybe even "imagine communism." 46

Translation:Jan Szelagiewicz

$45 \mathrm{Nycz}$, "W stronę," 246.

46 The title of the spectacle Imagine-Communism was originally suggested by Zygmunt Piotrowski. My thanks to Mrs. Zofia Kulik for clearing that up. 